Article

\title{
Numerical Analysis of the Factors Influencing a Vertical U-Tube Ground Heat Exchanger
}

\author{
Shangyuan Chen, Jinfeng Mao *, Xu Han *, Chaofeng Li and Liyao Liu \\ Institute of Military Environmental Teaching and Research, PLA University of Science and Technology, \\ Nanjing 210007, China; ahsscsy@163.com (S.C.); lichaofeng789@hotmail.com (C.L.); lly19930317@126.com (L.L.) \\ * Correspondence: maojinfeng628@163.com (J.M.), hanx@vip.163.com (X.H.); \\ Tel.: +86-25-8082-5331 (J.M.); +86-25-8082-5321 (X.H.)
}

Academic Editor: Andrew Kusiak

Received: 29 June 2016; Accepted: 30 August 2016; Published: 1 September 2016

\begin{abstract}
The development of a three-dimensional, unsteady state model, which couples heat transfer with groundwater seepage for a vertical U-tube ground heat exchanger (GHE) is presented. The influence of underground soil thermal properties, grout materials, inlet water temperature and velocity, and groundwater seepage on heat transfer in the GHE is examined. The results indicate that before the heat in the borehole is saturated, the heat flux in the GHE is directly proportional to the thermal conductivity coefficient of the grout materials. The radius of the thermal effect of the GHE and the recovery rate of the temperature in the soil are also proportional to the thermal diffusion coefficient of the soil. In cooling mode, the increase of the inlet water temperature of the GHE results in enhanced heat transfer. However, this may cause issues with heat buildup. The increase of the inlet water velocity in the GHE enhances heat convection in the tube. The effect of thermal-seepage coupling in groundwater can reduce the accumulated heat, thus resulting in the effective enhancement of the heat transfer in the GHE.
\end{abstract}

Keywords: influence factors; ground heat exchanger; heat flux

\section{Introduction}

Ground-source heat-pump (GSHP) systems have been widely applied due to their advantages in efficiency, energy conservation, and emission reduction. The GSHP systems use geothermal energy from shallow earth layers as a heat source or a heat sink, and absorb or emit heat to the underground through ground heat exchangers (GHE) to provide refrigeration or heat supply to buildings [1-4]. Their first application was in the USA in 1945. The GSHP, as an innovative device, succeeded in revealing its great advantages [5].The ability of a GHE mainly depends on the structure and thermal properties of the surroundings as well as on the operating conditions. To ensure the performance of a GSHP, the careful design of GHEs is essential [6,7].

Various types of GHEs are available on the market. The vertical U-tubes, which are inserted into a borehole and often backfilled with cement, bentonite and sand, are very efficient, but the drilling cost is rather high. Thus, a lot of researchers have aimed to improve the performance of GHEs and reduce the borehole depth [8]. Jalaluddin and Miyara [9] built three GHE models, including U-tube, double-tube, and multi-tube, to investigate the effect of tube number. Based on simulation results, during cooling mode, the heat flux of GHE at $22 \mathrm{~h}$ increased by $23.7 \%$ for the double-tube and $54.2 \%$ for the multi-tube. This indicated that the increase in tube number provided a possibility to improve the thermal performance and reduce the drilling cost of the GHEs.

The horizontal and helically coiled GHEs are also good choices for high-efficiency and low-cost [10,11]. Congedo et al. [12] investigated three different tubes (linear, helical and slinky) that influence the 
performance of GHE by CFD simulations, and the analysis revealed that the helical heat exchanger arrangement performed the best.

The shank spacing is also one of the structural factors on which this study is focused. In order to investigate the factors influencing thermal conductivity and thermal borehole resistance, a sensitivity study based on numerical simulations, considering the effects of the shank spacing, initial thermal distribution and thermal dispersivity, was performed by Wagner et al. [13]. It was demonstrated that the effects of the first two parameters were just below $10 \%$. On the other hand, thermal dispersivity plays a key role because its influence overestimates the effective thermal conductivity by a factor of 1.2-2.9 as compared to the saturated condition.

Bouhacina et al. [14] added longitudinal fins to the inner surface of the U-tube to obtain a novel GHE, and then the effects and benefits of this novel GHE were studied numerically. Two models were built to simulate the thermal and dynamic behaviors of a traditional GHE and the novel GHE. The result showed that under the same inlet condition, a greater velocity was noticed in the case of the novel GHE, and the heat exchange was up to $7 \%$ more efficient.

Thermal properties have also been considered. Three parameters of the GHE, including subsurface thermophysical properties, pipe materials and operating modes, were investigated by Lous et al. [15]. The results showed that the porosity, thermal conductivities, and geothermal flux play an important role in the heat transfer. Furthermore, the parameters that affect thermal comportment are primarily the thermal conductivity of the U-tube, the discharge rate of the circulating water and the heat flux.

Several studies have taken the influence of convection into consideration. A CFD simulation of the U-tube was considered by Gustafsson et al. [16]. A temperature gradient was obtained by setting a lower temperature on the far-field wall and a higher temperature on the tube wall, which induced a velocity gradient in the underground water. This resulted in an increased heat flux. Yang et al. [17] developed a GHE model that accounts for groundwater advection in a porous media to investigate the influence of groundwater on the thermal distribution. It was discovered that better diffusivity conditions can increase the rate of soil heat diffusion. Thus, the heat buildup can be alleviated. In addition, groundwater advection can efficiently remove the underground heat buildup. Dehkordi and Schincariol [18] used a fully discretized finite-element model to evaluate the thermal effect and hydrogeological properties of a GHE. The sensitivity of major parameters and thermo-hydrogeological factors that influence the system's performance, as well as their impact, were analyzed over 6-month and 25-year operation periods. The results indicated that the groundwater flow $\left(>10^{-7} \mathrm{~m} / \mathrm{s}\right)$, thermal conductivity and thermal gradient between the background and inlet result in a more efficient heat exchange. However, the effect of thermal interference between the branch tubes was overlooked while analyzing the grout thermal conductivity. It can be proved that the thermal interference would be enhanced, and then the GHE efficiency reduced by using thermally enhanced grout.

However, these studies did not thoroughly consider the influencing factors; therefore a comparative analysis is required. In this paper, the vertical GHE applied under different scenarios is evaluated. A three-dimensional unsteady state model for heat transfer in the vertical U-tube GHE is developed, and the influence of underground soil thermal properties, grout materials, inlet water temperature and velocity, and groundwater seepage on the heat transfer in the GHE is analyzed. In the discussion on heat flux, the factors are investigated from different aspects in detail such as the thermal-seepage coupling, thermal interference between branch tubes, turbulent flow in tubes, and recovery of ground temperature.

\section{Methods}

\subsection{Model Description}

As shown in Figure 1, a U-tube with an outer diameter of $37 \mathrm{~mm}$ and thickness of $2.5 \mathrm{~mm}$ is inserted into a $150 \mathrm{~mm}$ borehole at a depth of $100 \mathrm{~m}$, while the distance between the two tubes is $50 \mathrm{~mm}$. 
The assumptions that have been applied in the model are: (i) the physical properties of both soil and grout are homogenous and isotropic; (ii) the contact thermal resistances of joints are negligible; (iii) the soil is a saturated porous medium and (iv) the underground water seepage flow is horizontal. All the simulations were performed using the commercial Fluent 6.3 CFD software (Fluent, Inc., New York, NY, USA) and the Gambit 2.0 preprocessor (Fluent, Inc.).

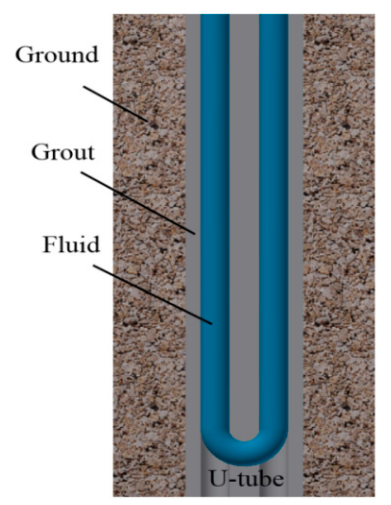

Figure 1. The schematic illustration of GHE.

It is reasonable to refine the mesh along the horizontal plane and coarsen that along the vertical plane. As shown in Figure 2, the ground and grout domain is meshed using triangular elements, the fluid domain is meshed using quadrangular elements, the U-tube is meshed using boundary layer elements, the curving section is meshed with 15 interval counts and the overall volume grid is generated by sweeping the model with a space of $0.5 \mathrm{~m}$.
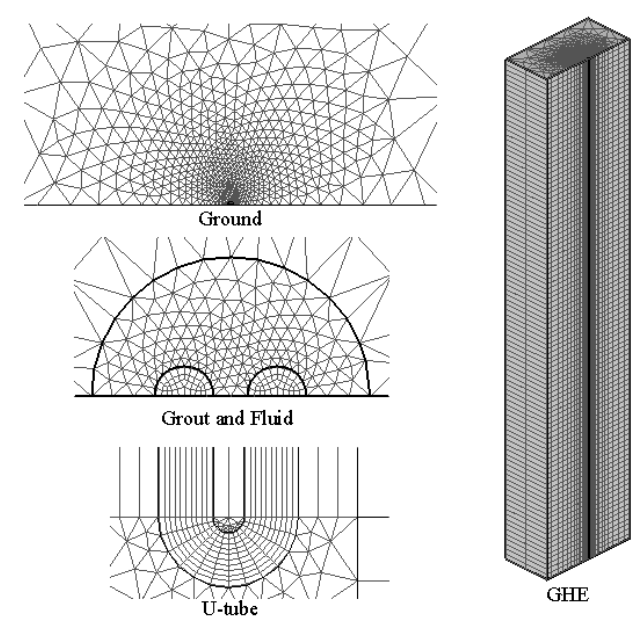

Figure 2. The finite elements of GHE.

A mesh convergence study was performed by comparing the simulations and the Chen et al. [19] experiment. The results in Table 1 show the difference in heat flux based on three types of mesh density. The finer mesh produced the minimum error $(0.6 \%)$ and was adopted to simulate the GHE. The model is able to predict the heat flux very accurately.

Table 1. Mesh convergence study.

\begin{tabular}{ccccc}
\hline & Coarse Mesh & Medium Mesh & Finer Mesh & Experiment \\
\hline Mesh number & 353,127 & 485,227 & 692,570 & - \\
Heat flux $(\mathrm{W} /(\mathrm{m} \cdot \mathrm{K}))$ & 51.81 & 52.77 & 53.62 & 53.31 \\
Difference $(\%)$ & 2.81 & 1.01 & 0.6 & \\
\hline
\end{tabular}




\subsection{The Governing Equations}

The generalized equation can be expressed as [20]:

$$
\frac{\partial(\rho \varnothing)}{\partial \tau}+\operatorname{div}(\rho \mathbf{U} \varnothing)=\operatorname{div}\left(\Gamma_{\varnothing} \operatorname{grad} \varnothing\right)+S_{\varnothing}
$$

The $k$ and $\varepsilon$ realizable equations, which characterize the turbulent flow, can be expressed as follows [21]:

$$
\begin{gathered}
\frac{\partial(\rho k)}{\partial \tau}+\frac{\partial\left(\rho k u_{i}\right)}{\partial x_{i}}=\frac{\partial}{\partial x_{j}}\left[\left(\mu+\frac{\mu_{t}}{\sigma_{k}}\right) \frac{\partial k}{\partial x_{j}}\right]+G_{k}-\rho \varepsilon \\
\frac{\partial(\rho \varepsilon)}{\partial \tau}+\frac{\partial\left(\rho \varepsilon u_{i}\right)}{\partial x_{i}}=\frac{\partial}{\partial x_{j}}\left[\left(\mu+\frac{\mu_{t}}{\sigma_{\varepsilon}}\right) \frac{\partial \varepsilon}{\partial x_{j}}\right]+\rho C_{1} E \varepsilon-C_{2} \rho \frac{\varepsilon^{2}}{k+\sqrt{k v \varepsilon}}
\end{gathered}
$$

where $\mu, v$, and $\mu_{t}$ are the dynamic viscosity, kinematic viscosity, and turbulent viscosity, respectively; $G_{k}$ and $E$ are the production terms of $k$ and $\varepsilon ; \sigma_{k}$ and $\sigma_{\varepsilon}$ are the Prandtl number of $k$ and $\varepsilon$ with values of 1.0 and 1.2, respectively; $C_{1}$ and $C_{2}$ are empirical constants.

The momentum equation of the soil has an additional source item, which is the viscosity loss of underground water [22]; the equation can be expressed as:

$$
S_{u}=\frac{\mu}{\alpha} u
$$

where $S_{u}$ is the source term; $\alpha$ and $u$ are the soil permeability and groundwater flow velocity, respectively.

The energy equations of the soil can be divided into two parts:

One part is the solid phase of soil:

$$
(1-\varphi)\left(\rho c_{p}\right)_{s} \frac{\partial T}{\partial \tau}=(1-\varphi) \lambda_{s} \frac{\partial^{2} T}{\partial x_{i}}
$$

The other part is the fluid phase of underground water:

$$
\varphi\left(\rho c_{p}\right)_{f} \frac{\partial T}{\partial \tau}+\varphi\left(\rho c_{p}\right)_{f} u_{i} \frac{\partial T}{\partial x_{i}}=\varphi \lambda_{f} \frac{\partial^{2} T}{\partial x_{i}}
$$

The total equation can be expressed as [23]:

$$
\left[(1-\varphi)\left(\rho c_{p}\right)_{s}+\varphi\left(\rho c_{p}\right)_{f}\right] \frac{\partial T}{\partial \tau}+\varphi\left(\rho c_{p}\right)_{f} u_{i} \frac{\partial T}{\partial x_{i}}=\left[(1-\varphi) \lambda_{s}+\varphi \lambda_{f}\right] \frac{\partial^{2} T}{\partial x_{i}}
$$

where $\varphi$ is the soil porosity.

\subsection{Data Processing}

The initial and boundary conditions are set as follows:

(1) The initial temperature is a constant of $290.6 \mathrm{~K}$.

(2) The far-field and bottom surfaces are set as undisturbed boundaries.

(3) The top ground surface is set as a convective boundary with an air temperature of $289.0 \mathrm{~K}$ and a heat transfer coefficient of $10 \mathrm{~W} /\left(\mathrm{m}^{2} \cdot \mathrm{K}\right)$.

(4) The inlet is set as a velocity-inlet boundary, and the outlet is set as a pressure-outlet boundary.

(5) The reference parameters for simulation are listed in Table 2. 
Table 2. The reference parameters of GHE for simulation.

\begin{tabular}{ccc}
\hline Parameters & Units & Values \\
\hline Soil thermal conductivity & $\mathrm{W} /(\mathrm{m} \cdot \mathrm{K})$ & 2 \\
Soil density & $\mathrm{kg} / \mathrm{m}^{3}$ & 2183 \\
Soil heat capacity & $\mathrm{J} /(\mathrm{kg} \cdot \mathrm{K})$ & 996 \\
Soil porosity & $\%$ & 39 \\
Soil permeability & $\mathrm{m}^{2}$ & $2.3 \times 10^{-10}$ \\
Grout thermal conductivity & $\mathrm{W} /(\mathrm{m} \cdot \mathrm{K})$ & 2 \\
Grout density & $\mathrm{kg} / \mathrm{m}^{3}$ & 2500 \\
Grout heat capacity & $\mathrm{J} /(\mathrm{kg} \cdot \mathrm{K})$ & 1110 \\
Inlet temperature & $\mathrm{K}$ & 303 \\
Inlet velocity & $\mathrm{m} / \mathrm{s}$ & 0.3 \\
Groundwater seepage & $\mathrm{m} / \mathrm{s}$ & 0 \\
\hline
\end{tabular}

The overall heat transfer capacity of GHE can be expressed as Equation (8):

$$
q_{l}=\left(\rho c_{p}\right)_{f} v_{\text {in }}\left(T_{\text {in }}-T_{\text {out }}\right) / H
$$

where $q_{l}$ is the heat flux per unit borehole depth; $\left(\rho c_{p}\right)_{f}$ is the volumetric heat capacity; $v_{i n}$ is the inlet flow; $T_{\text {in }}$ and $T_{\text {out }}$ are the temperatures of inlet and outlet, respectively; $H$ is the borehole depth.

\section{Analysis of Influencing Factors of Heat Transfer}

\subsection{Influence of Grout Materials}

Cement, bentonite, or sand are generally used as grout materials in engineering practice; the thermophysical properties of these materials vary significantly. Three different grout materials are selected for the analyses and their parameters are shown in Table 3.

Table 3. The thermophysical properties of the grout materials.

\begin{tabular}{ccccc}
\hline \multirow{2}{*}{ Grout } & Density & Specific Heat & Thermal Conductivity Coefficient & Thermal Diffusion Coefficient \\
\cline { 2 - 5 } & $\mathbf{k g} / \mathbf{m}^{\mathbf{3}}$ & $\mathbf{J} / \mathbf{( k g} \cdot \mathbf{K})$ & $\mathbf{W} / \mathbf{( m \cdot K )}$ & $\mathbf{m}^{\mathbf{2}} / \mathbf{s}$ \\
\hline Bentonite & 2600 & 720 & 1.6 & $8.5 \times 10^{-7}$ \\
Sand & 2500 & 1110 & 2.0 & $7.2 \times 10^{-7}$ \\
Cement & 1631 & 900 & 2.8 & $1.9 \times 10^{-6}$ \\
\hline
\end{tabular}

The heat flux histories for the different grout materials are shown in Figure 3. During the initial period, heat transfer in the GHE is concentrated in the inside part of the borehole. The heat flux is determined by the thermophysical properties of the grout materials, and is found to be the highest when cement is used for grout. After some time, the heat is accumulated to a certain quantity and the heat flux is determined by the thermophysical properties of the soil outside the borehole. Therefore, the difference in the heat flux is reduced after $10 \mathrm{~h}$.

As shown in Figure 4, the fluid temperature in the U-tube decreases along the fluid path. The reduction in the temperature reaches its highest value when the cement grout is used. The temperature of sand and cement grout increases near the outlet tube, which has an unfavorable effect on the heat transfer because the heat in the inlet tube is transferred to the outlet tube by the grout materials within a narrow distance $(50 \mathrm{~mm})$. Therefore, the temperature in the outlet tube rises again and its recovery depends on how high the thermal conductivity coefficient is of the grout materials. 


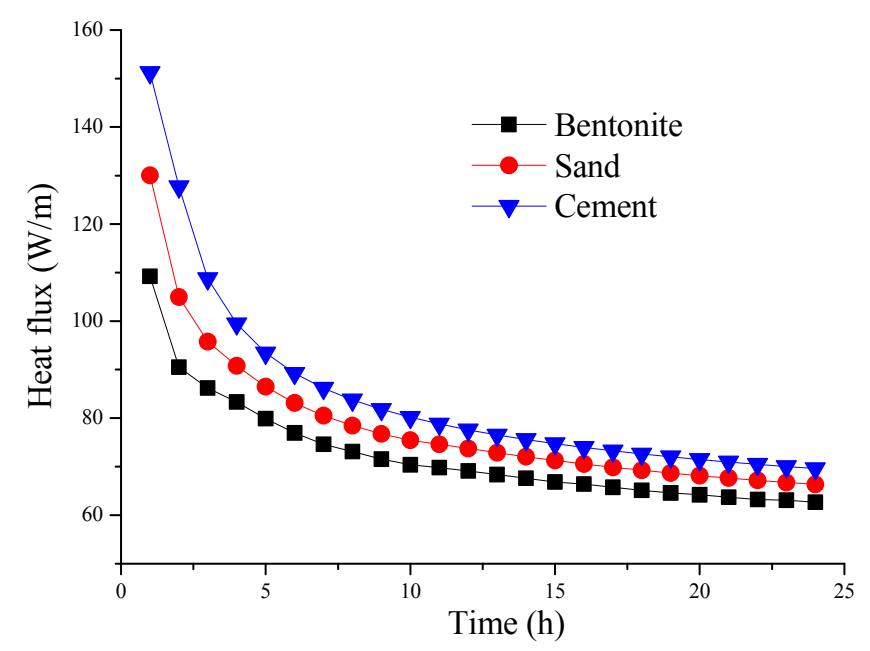

Figure 3. Heat flux variation for the different grout materials.

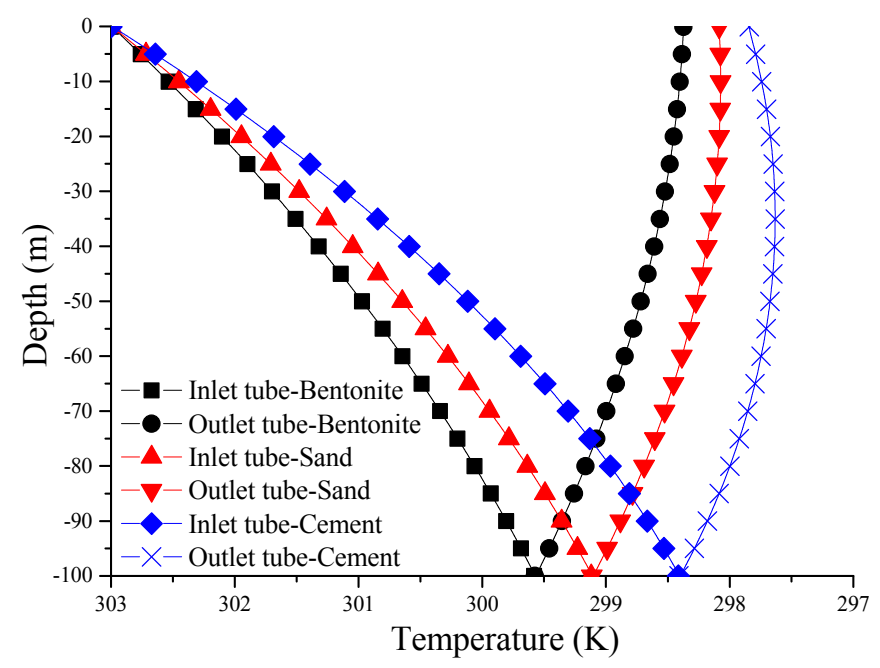

Figure 4. Temperature in both inlet and outlet tubes for the different grout materials.

\subsection{Influence of Soil}

Three different soils are selected and the parameters are listed in Table 4. The heat flux histories are shown in Figure 5. The greater the thermal conductivity coefficient of the soil, the higher the heat flux of the GHE. The heat flux reaches its highest value when the ground materials are composed of granites. At the beginning, the difference in the heat flux is small and it increases with time as the heat diffuses towards the soil regions.

Table 4. The thermophysical properties of the soils.

\begin{tabular}{ccccc}
\hline \multirow{2}{*}{ Soils } & Density & Specific Heat & Thermal Conductivity Coefficient & Thermal Diffusion Coefficient \\
\cline { 2 - 5 } & $\mathbf{k g} / \mathbf{m}^{\mathbf{3}}$ & $\mathbf{J} / \mathbf{k g} \cdot \mathbf{K})$ & $\mathbf{W} / \mathbf{( m} \cdot \mathbf{K})$ & $\mathbf{m}^{\mathbf{2}} / \mathbf{s}$ \\
\hline Silt & 1760 & 1510 & 1.6 & $6.0 \times 10^{-7}$ \\
Sand & 2500 & 1110 & 2.0 & $7.2 \times 10^{-7}$ \\
Granite & 2500 & 840 & 2.4 & $1.14 \times 10^{-6}$ \\
\hline
\end{tabular}




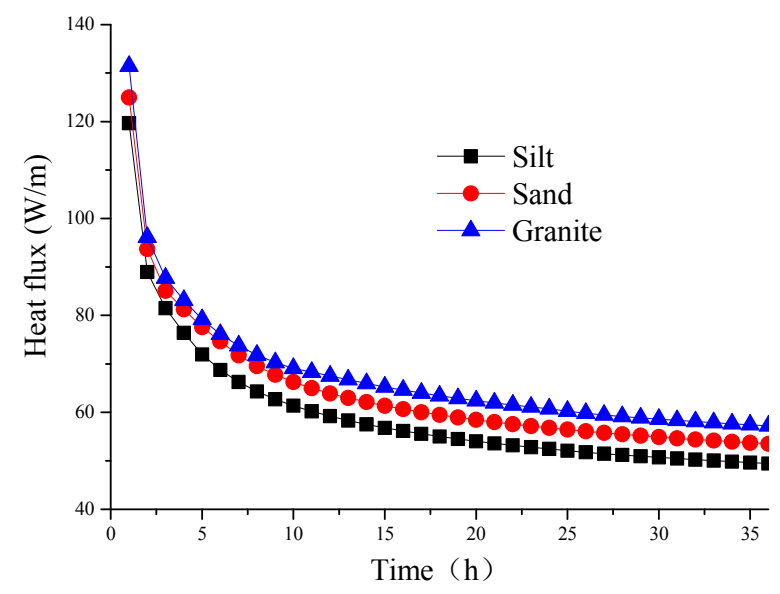

Figure 5. Heat flux variation for the different soils.

The field temperature at a depth of $20 \mathrm{~m}$ under the ground after 30 days of continuous operation in the borehole and another 10 days of a natural recovery period is shown in Figure 6 . The heat is transferred from the center of the borehole to its far ends, with the highest temperature at the center of the borehole. The higher the value of the thermal diffusion coefficient of soil, the larger its radius of thermal effect. After 30 days, the radius of thermal effect values for silt, sand, and granite are $1.68 \mathrm{~m}$, $1.78 \mathrm{~m}$, and $1.95 \mathrm{~m}$, respectively.

The temperature at the center decreases during the natural recovery period. The temperature in the soil gradually recovers and its rate can be estimated using Equation (9):

$$
\xi=\frac{T-T^{\prime}}{T-T_{0}}
$$

where $T_{o}$ is initial soil temperature, $T$ is the soil temperature under continuous operation, $T^{\prime}$ is the soil temperature after recovery. The recovery rate of the field temperature in silt, sand, and granite are $0.773,0.778$, and 0.789 , respectively. Therefore, the higher the thermal diffusion coefficient of the soil, the faster the natural recovery of the ground temperature.

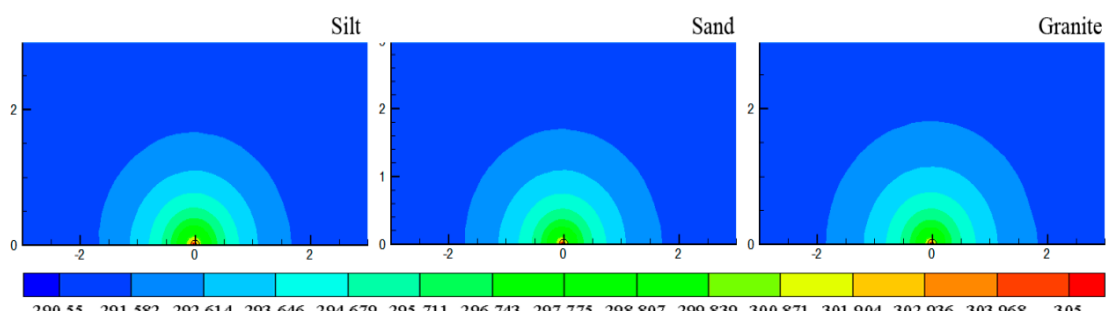

(a)

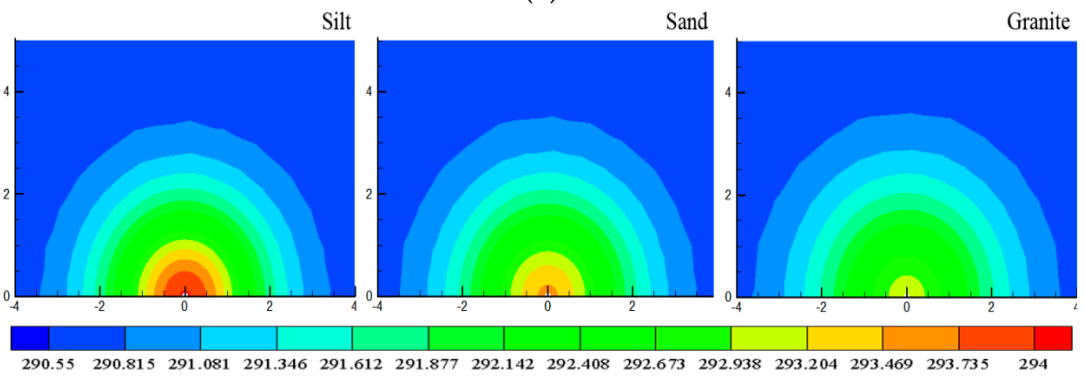

(b)

Figure 6. Temperature distributions under the ground for the different soils. (a) After a continuous operation of 30 days; (b) after a natural recovery of 10 days. 


\subsection{Influence of Inlet Water Temperature}

Three different inlet water temperatures of $298 \mathrm{~K}, 303 \mathrm{~K}$, and $308 \mathrm{~K}$ are selected, and the heat flux histories are shown in Figure 7; with the increase of the inlet temperature, the temperature potential to initial ground temperature increases and the heat transfer capacity of the GHE is higher. The heat flux in the GHE is the highest when inlet water temperature is $308 \mathrm{~K}$, with an average value of $87.8 \mathrm{~W} / \mathrm{m}$.

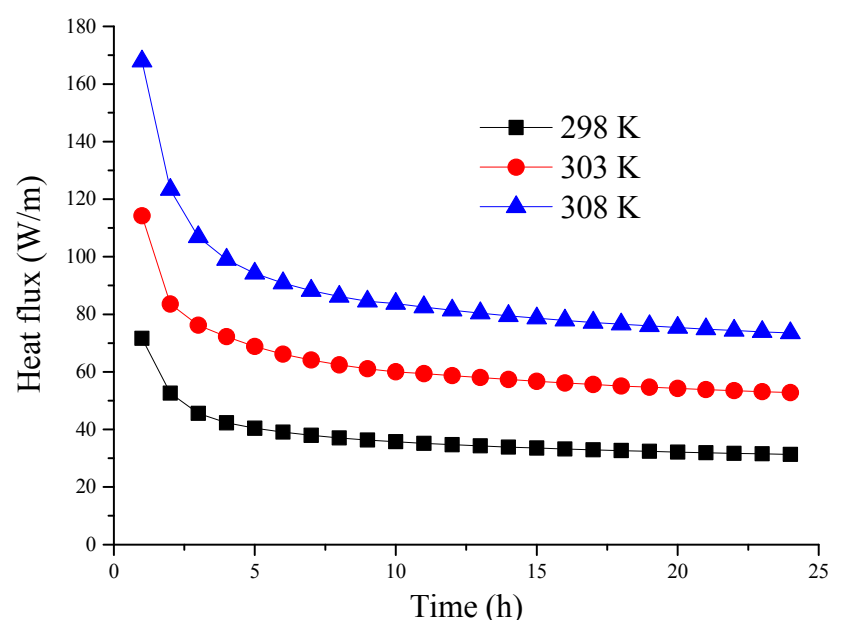

Figure 7. Heat flux variation for the different inlet temperatures.

The field temperature at a depth of $20 \mathrm{~m}$ under the ground is shown in Figure 8; the higher the value of the inlet water temperature, the higher the rise in the underground field temperature. When the inlet water temperature values are $298 \mathrm{~K}, 303 \mathrm{~K}$, and $308 \mathrm{~K}$, the borehole wall temperature values are $294 \mathrm{~K}, 297.3 \mathrm{~K}$, and $301.2 \mathrm{~K}$, respectively. The radius of thermal effect values are $0.26 \mathrm{~m}$, $0.35 \mathrm{~m}$, and $0.42 \mathrm{~m}$, respectively. The heat in the underground will be accumulated if the inlet water temperature is too high, which has a negative effect on long-term operation of GHEs.

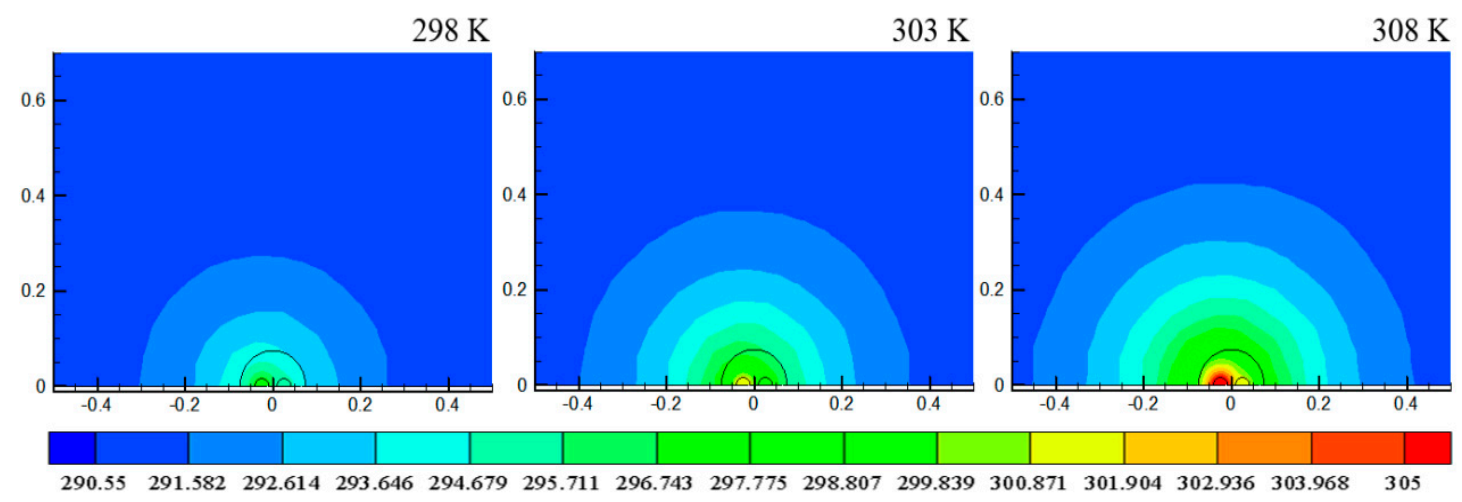

Figure 8. Temperature distributions under the ground for different inlet temperatures.

\subsection{Influence of Inlet Water Velocity}

Three different inlet water velocities of $0.2 \mathrm{~m} / \mathrm{s}, 0.3 \mathrm{~m} / \mathrm{s}$ and $0.6 \mathrm{~m} / \mathrm{s}$ are selected and the heat flux histories are shown in Figure 9; the heat flux increases with the increase in the inlet water velocity. When the inlet water velocity is $0.6 \mathrm{~m} / \mathrm{s}$, the heat flux in the GHE is the highest, with an average value of $76 \mathrm{~W} / \mathrm{m}$. This is mainly because the heat-carrying fluid flow increases with the increase of the flow velocity. 


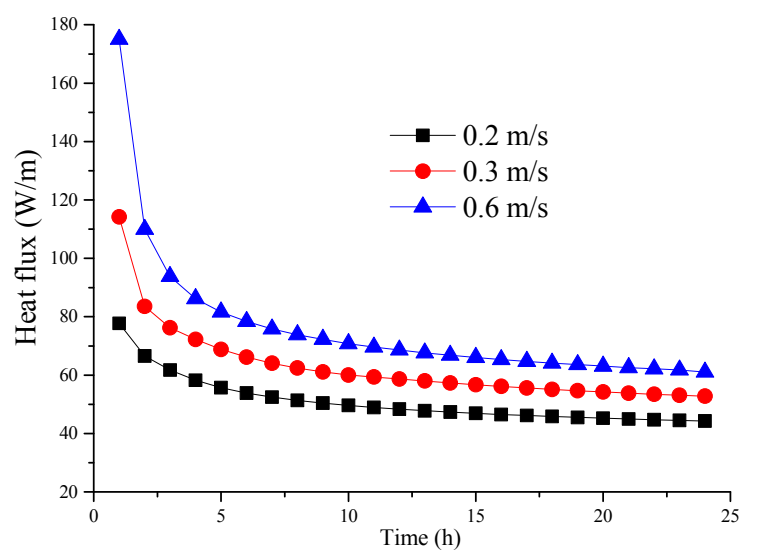

Figure 9. Heat flux variation for the different inlet velocities.

Meanwhile, with the increase in the flow velocity, the diffusion rate of kinetic energy increases, the heat transfer in turbulent flow is strengthened, and the surface heat transfer coefficient is higher. The heat transfer coefficient, Reynolds and Nusselt numbers are calculated by the method of surface integral weighted average as:

$$
\varnothing=\frac{1}{\mathrm{~A}} \int \varnothing \mathrm{dA}
$$

where $\varnothing$ is the variable through surface A. The results of interior flow are shown in Table 5 ; when the inlet water velocity values are $0.2 \mathrm{~m} / \mathrm{s}, 0.3 \mathrm{~m} / \mathrm{s}$, and $0.6 \mathrm{~m} / \mathrm{s}$, the computed average surface heat transfer coefficients are $17.97 \mathrm{~W} /\left(\mathrm{m}^{2} \cdot \mathrm{K}\right), 21.06 \mathrm{~W} /\left(\mathrm{m}^{2} \cdot \mathrm{K}\right)$, and $25.95 \mathrm{~W} /\left(\mathrm{m}^{2} \cdot \mathrm{K}\right)$, respectively.

Table 5. The results of interior flow.

\begin{tabular}{cccc}
\hline Inlet Velocity & Reynolds Numbers & Nusselt Numbers & Heat Transfer Coefficient \\
\hline $\mathbf{m} / \mathbf{s}$ & - & - & $\mathbf{W} /\left(\mathbf{m}^{\mathbf{2}} \cdot \mathbf{K}\right)$ \\
\hline 0.2 & 6568 & 29.95 & 17.97 \\
0.3 & 9852 & 35.09 & 21.06 \\
0.6 & 19,705 & 43.25 & 25.95 \\
\hline
\end{tabular}

\subsection{Influence of Groundwater Flow}

The change in the heat flux when the Darcy velocities are set at $2 \times 10^{-7} \mathrm{~m} / \mathrm{s}, 2 \times 10^{-6} \mathrm{~m} / \mathrm{s}$, and $2 \times 10^{-5} \mathrm{~m} / \mathrm{s}$ is shown in Figure 10. During the initial period, the seepage in the ground can remove some of the heat and reduce the borehole wall temperature. Therefore, the heat flux in the case of seepage is higher than that in the case of no seepage. However, after the heat in the borehole is accumulated for a certain period, e.g., after $5 \mathrm{~h}$, groundwater with the Darcy velocity of $2 \times 10^{-7} \mathrm{~m} / \mathrm{s}$ can no longer reduce the borehole wall temperature effectively, and the heat transfer intensity in the GHE is close to that in the case of no seepage. When the Darcy velocity is $2 \times 10^{-6} \mathrm{~m} / \mathrm{s}$, the same case described above occurs after $20 \mathrm{~h}$. When the Darcy velocity is increased to $2 \times 10^{-5} \mathrm{~m} / \mathrm{s}$, it has medium water permeability. The positive effect induced by the thermal-seepage coupling exceeds the negative effect caused by heat buildup, and the heat transfer process is improved.

As shown in Figure 11, when a Darcy velocity is $2 \times 10^{-7} \mathrm{~m} / \mathrm{s}$, it basically belongs to an impermeable stratum, and the temperature distribution is generally the same as that in the case of no seepage. When the Darcy velocity is $2 \times 10^{-6} \mathrm{~m} / \mathrm{s}$, the ability of heat diffusion is improved. When the Darcy velocity is $2 \times 10^{-5} \mathrm{~m} / \mathrm{s}$, the thermal-seepage coupling effect causes the contour line to shift towards the seepage direction, and the radius of the thermal effect around the borehole is significantly reduced. 


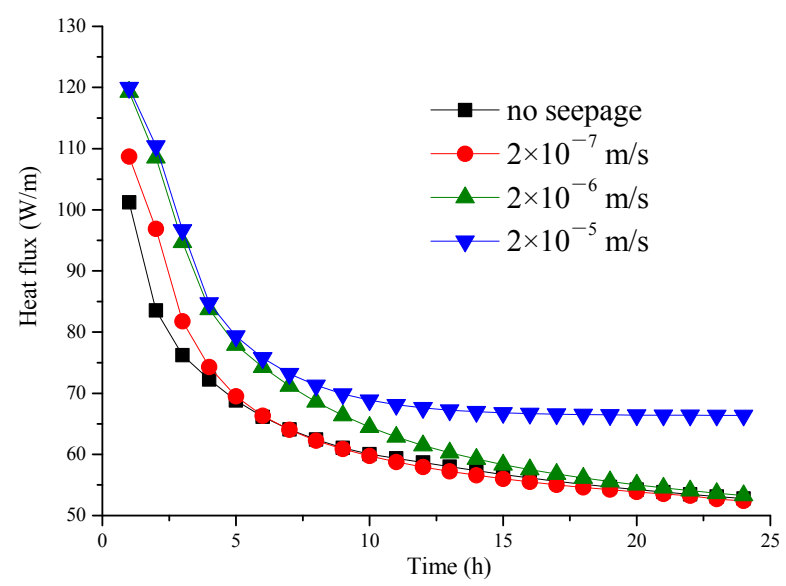

Figure 10. Heat flux variation for the different groundwater seepage values.

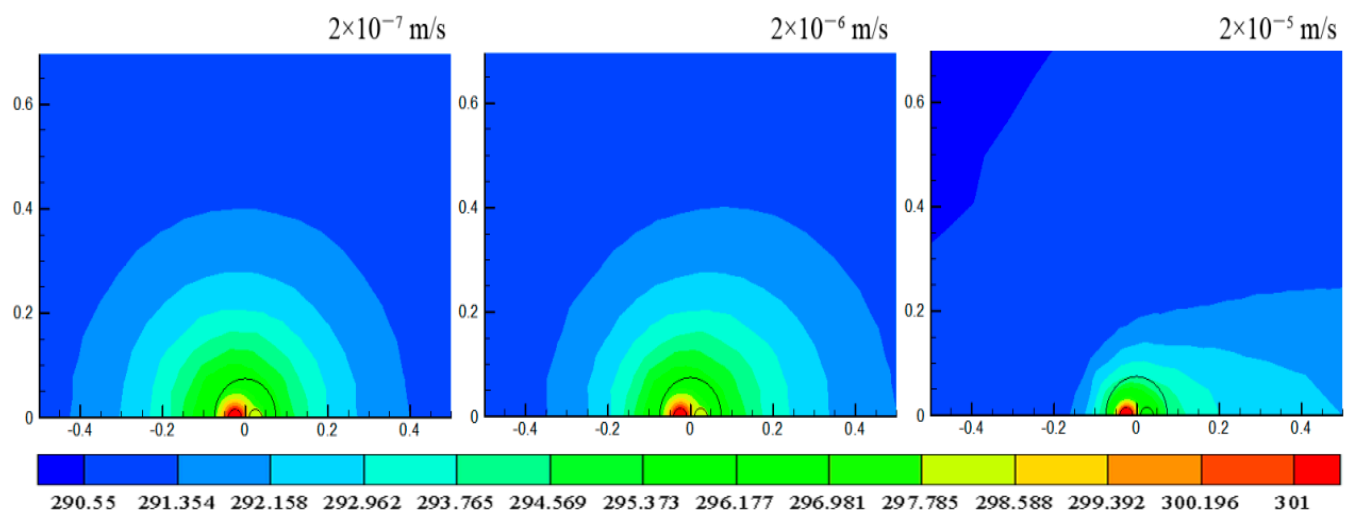

Figure 11. Temperature distributions under the ground for different groundwater seepage values.

\section{Conclusions}

The vertical U-tube GHE is thoroughly evaluated in this study. A three-dimensional unsteady state model coupling heat transfer with groundwater seepage is developed, and the model has been validated with GHE experimental data. A large number of simulations are employed to investigate factors influencing the vertical GHE. The analysis is compared based on the heat flux in the borehole, fluid temperature along the U-tube, thermal interference between branches, turbulent flow in tubes, and temperature recovery in the ground.

The results clearly show the importance of underground soil thermal properties, grout materials, inlet water temperature and velocity, and groundwater seepage on thermal performance. The conclusions can be drawn as:

(1) Before the heat in the borehole is saturated, the heat flux in the GHE is directly proportional to the thermal conductivity coefficient of the grout materials.

(2) The greater the thermal diffusion coefficient of the soil materials, the larger the radius of the thermal effect of the GHE and the faster the recovery rate of the temperature in the soil.

(3) Increasing the inlet water temperature strengthens the heat transfer in the GHE, but it can cause heat buildup problems.

(4) Increasing the inlet water velocity can enlarge the heat convection in the tube; when the inlet water velocity values are $0.2 \mathrm{~m} / \mathrm{s}, 0.3 \mathrm{~m} / \mathrm{s}$, and $0.6 \mathrm{~m} / \mathrm{s}$, the computed average surface heat transfer coefficients are $17.97 \mathrm{~W} /\left(\mathrm{m}^{2} \cdot \mathrm{K}\right), 21.06 \mathrm{~W} /\left(\mathrm{m}^{2} \cdot \mathrm{K}\right)$, and $25.95 \mathrm{~W} /\left(\mathrm{m}^{2} \cdot \mathrm{K}\right)$, respectively.

(5) The thermal-seepage coupling effect in groundwater can remove the accumulated heat, and therefore, can effectively enhance the heat transfer in the GHE. 
Acknowledgments: This work was supported by PLA University of Science and Technology.

Author Contributions: Shangyuan Chen and Jinfeng Mao conceived the study plan. All authors contributed to the analysis of the data and to the writing of the manuscript. All authors read and approved the final manuscript.

Conflicts of Interest: The authors declare no conflict of interest.

\section{Nomenclature}

$\begin{array}{ll}\text { Main symbols } & \\ H & \text { borehole depth }(\mathrm{m}) \\ q_{l} & \text { heat flux per unit borehole depth }(\mathrm{W} / \mathrm{m}) \\ S & \text { source term } \\ T & \text { temperature }(\mathrm{K}) \\ u & \text { velocity vector } \\ u_{i} & \text { velocity components in } x_{i} \text { directions } \\ x_{i} & \text { Cartesian coordinates } \\ \text { Greek symbols } & \\ \alpha & \text { soil permeability }\left(\mathrm{m}^{2}\right) \\ \varepsilon & \text { turbulent dissipation rate }\left(\mathrm{m}^{2} / \mathrm{s}^{3}\right) \\ k & \text { turbulent kinematic energy }\left(\mathrm{m}^{2} / \mathrm{s}^{2}\right) \\ \lambda & \text { thermal conductivity }\left(\mathrm{W} / \mathrm{m}^{2} \cdot \mathrm{K}\right) \\ \mu & \text { dynamic viscosity }\left(\mathrm{N} \cdot \mathrm{s} / \mathrm{m}^{2}\right) \\ \mu_{t} & \text { turbulent viscosity }\left(\mathrm{N} \cdot \mathrm{s} / \mathrm{m}^{2}\right) \\ v_{i n} & \text { inlet flow }\left(\mathrm{m}^{3} / \mathrm{h}\right) \\ \xi & \text { temperature recovery rate } \\ \rho & \text { density }\left(\mathrm{kg} / \mathrm{m}^{3}\right) \\ \rho c_{p} & \text { volumetric heat capacity }\left(\mathrm{kJ} /\left(\mathrm{m}^{3} \cdot \mathrm{K}\right)\right) \\ \tau & \text { time }(\mathrm{h}) \\ \varphi & \text { soil porosity } \\ \varnothing & \text { generalized variable } \\ \text { Subscripts } & \\ f & \text { inderground water } \\ \text { in } \text { out } & \text { soil and outlet } \\ \mathrm{s} & \\ & \end{array}$

\section{References}

1. Sarbu, I.; Sebarchievici, C. General review of ground-source heat pump systems for heating and cooling of buildings. Energy Build. 2014, 70, 441-454. [CrossRef]

2. Hepbasli, A. A key review on exergetic analysis and assessment of renewable energy resources for a sustainable future. Renew. Sustain. Energy Rev. 2008, 12, 593-661. [CrossRef]

3. Florides, G.; Kalogirou, S. Ground heat exchangers-A review of systems, models and applications. Renew. Energy 2007, 32, 2461-2478. [CrossRef]

4. Gao, Q.; Li, M.; Yu, M.; Spitler, J.D.; Yan, Y.Y. Review of development from GSHP to UTES in China and other countries. Renew. Sustain. Energy Rev. 2009, 13, 1383-1394. [CrossRef]

5. Sanner, B.; Karytsas, C.; Mendrinos, D.; Rybach, L. Current status of ground source heat pumps and underground thermal energy storage in Europe. Geothermics 2003, 32, 579-588. [CrossRef]

6. Liu, X.B.; Lu, S.L.; Hughes, P.; Cai, Z. A comparative study of the status of GSHP applications in the United States and China. Renew. Sustain. Energy Rev. 2015, 48, 558-570. [CrossRef]

7. Eskilson, P. Thermal Analysis of Heat Extraction Boreholes. Ph.D. Thesis, University of Lund, Lund, Sweden, 1987.

8. Yang, H.; Cui, P.; Fang, Z. Vertical-borehole ground-coupled heat pumps: A review of models and systems. Appl. Energy 2010, 87, 16-27. [CrossRef] 
9. Jalaluddin; Miyara, A. Thermal performance investigation of several types of vertical ground heat exchangers with different operation mode. Appl. Therm. Eng. 2012, 33, 167-174.

10. Starace, G.; Congedo, P.M.; Colangelo, G. Horizontal heat exchangers for GSHPs. Efficiency and cost investigation for three different applications. In Proceedings of the 18th International Conference on Efficiency, Cost, Optimization, Simulation, and Environmental Impact of Energy Systems (ECOS 2005), Trondheim, Norway, 20-22 June 2005.

11. Jayakumar, J.S.; Mahajani, S.M.; Mandal, J.C.; Vijayan, P.K.; Bhoi, R. Experimental and CFD estimation of heat transfer in helically coiled heat exchangers. Chem. Eng. Res. Des. 2008, 86, 221-232. [CrossRef]

12. Congedo, P.M.; Colangelo, G.; Starace, G. CFD simulations of horizontal ground heat exchangers: A comparison among different configurations. Appl. Therm. Eng. 2012, 33, 24-32. [CrossRef]

13. Wagner, V.; Bayer, P. Numerical sensitivity study of thermal response tests. Renew. Energy 2012, 41, $245-253$. [CrossRef]

14. Bouhacina, B.; Saim, R.; Oztop, H.F. Numerical investigation of a novel tube design for the geothermal borehole heat exchanger. Appl. Therm. Eng. 2015, 79, 153-162. [CrossRef]

15. Lous, M.L.; Larroque, F. Thermal performance of a deep borehole heat exchanger: Insights from a synthetic coupled heat and flow model. Geothermics 2015, 57, 157-172. [CrossRef]

16. Gustafsson, A.M.; Westerlund, L.; Hellström, G. CFD-modeling of natural convection in a groundwater-filled borehole heat exchanger. Appl. Therm. Eng. 2010, 30, 683-691. [CrossRef]

17. Yang, W.B.; Chen, Y.P. Numerical investigation on the underground thermal imbalance of ground-coupled heat pump operated in cooling-dominated district. Appl. Therm. Eng. 2013, 58, 626-637. [CrossRef]

18. Dehkordi, S.E.; Schincariol, R.A. Effect of thermal-hydrogeological and borehole heat exchanger properties on performance and impact of vertical closed-loop geothermal heat pump systems. Hydrogeol. J. 2014, 22, 189-203. [CrossRef]

19. Chen, S.Y.; Mao, J.F. Heat transfer analysis of a vertical ground heat exchanger using numerical simulation and multiple regression model. Energy Build. 2016, 129, 81-91. [CrossRef]

20. Kaltreider, C.; Krarti, M.; McCartney, J. Heat transfer analysis of thermo-active foundations. Energy Build. 2015, 86, 492-501. [CrossRef]

21. Walton, W.C. Practical Aspects of Groundwater Modeling-Flow, Mass and Heat Transport and Subsidence and Computer Models; National Water Well Association: Westerville, OH, USA, 1985.

22. Molina-Giraldo, N.; Bayer, P.; Blum, P. Evaluating the influence of thermal dispersion on temperature plumes from geothermal systems using analytical solutions. Int. J. Therm. Sci. 2011, 50, 1223-1231. [CrossRef]

23. Campbell, G.S.; Jungbauer, J.D.; Bidlake, W.R.; Hungerford, R.D. Predicting the effect of temperature on soil thermal conductivity. Soil Sci. 1994, 158, 307-313. [CrossRef] 